\title{
Heat Transfer Enhancement in Absorber Tube of Parabolic Trough Concentrators Using Wire-Coils Inserts
}

\author{
Ketan Diwan, M.S. Soni" \\ Department of Mechanical Engineering, BITS Pilani, India
}

Copyright $@ 2015$ Horizon Research Publishing All rights reserved.

\begin{abstract}
Heat transfer enhancement technology provides many advantages in heat exchanger applications. In the present paper, the heat transfer characteristics and the pressure drops of the absorber tube of Parabolic Trough Concentrators with wire-coils inserts are investigated. Water is used as a heat transfer fluid and simulations are carried out in COMSOL Multiphysics ${ }^{\circledR} 4.4$, for various flow rates of water as well as for different pitch values of wire-coils insert. It is observed that introduction of wire coils increases the turbulence inside the tube, thereby increasing the Reynolds number and hence the Nusselt number. Value of Nusselt number is observed to be increased by $104 \%$ to $330 \%$ which indicates the increase in the value of convective heat transfer coefficient and hence the heat transfer rates.
\end{abstract}

Keywords Wire-coils, Parabolic Trough Concentrators, Mass Flow Rate, Nusselt Number, Convective Heat Transfer Coefficient, Solar Concentrator

\section{Introduction}

Tube inserts are the devices which are commonly used in Heat Exchangers for heat transfer augmentation. The advantage of using tube inserts is reduction of heat exchanger size which results into less capital cost. In addition, heat transfer enhancement enables heat exchanger to work at smaller velocity, but still achieves the same or even higher heat transfer coefficient. Considering all these advantages, experiments for checking performance of Solar Water Heaters (Thermosyphon or Tube on sheet) using tube inserts in collector tube started in 80s. These experiments successfully showed that, the use of tube inserts in Solar Water Heaters indeed causes heat transfer augmentation with improved thermal efficiency and hence performance of the system without appreciable cost increase. Till this date there is very extensive research has been done in Solar Water Heater systems using tube inserts. Parabolic Trough Concentrator (PTC) is the main technology currently in use for solar thermal electric power generation plants. Most of the work done on these systems is related to reduction of heat losses occurring from absorber tubes. Very little work has been carried out related to the heat transfer augmentation and that work is done using internally finned absorber tubes (Refer [2]). Till date no significant work has been published related to heat augmentation using tube inserts in PTCs.

Tube insert devices include twisted tape inserts, wire coils inserts, extended surface inserts, mesh inserts, and etc. out of which the use of twisted tapes and wire coils inserts is more common. Most of the work available today is based on the different twisted tape geometries. But, wire coils are the type of inserted devices which present some unique advantages compared to other enhancement techniques viz. they may be easily installed and that to with low cost in an existing smooth tube of heat exchanger and it also keeps the mechanical strength of the smooth tube.

\section{Literature Review}

Jaisankar et al. [1] in their work, using twisted tapes with different twist ratios in Solar Water Heater system did, the detail study of effect of friction factor on the thermal efficiency and heat transfer augmentation. They found that, the performance of solar water heater using twisted tape inserts is better than that of plain one and there can be $8-24 \%$ of reduction in area. Martin et al. [7] in their work used wired coils inserts instead of twisted tapes with water and propylene glycol as fluids. They found that there is about $400 \%$ increase in heat transfer for water and $44 \%$ for propylene glycol with the average increase of efficiency of 4.5\%. Kumar and Prasad's [3] work is considered to be very detail in terms of heat transfer, friction factor and thermal performance of solar water heater using twisted tapes. They found that the heat transfer due to twisted tape inserts increases by $18-70 \%$, whereas the pressure drop increases by $87-132 \%$, compared to plane collectors. Jaisankar et.al [9] in their another work on Thermosyphon solar heaters using twisted tapes with spacer at the trailing edge explained in detail, the effect of different twisted tapes geometries on thermal performance and other related parameters. Eck et al. [6] in their work gave Dynamics and control of parabolic trough collector loops with direct steam 
generation. Valenzuela et al. [4] and Odeh et al. [8] in their separate work gave control scheme for parabolic trough solar collectors for direct steam generation. Both these works are based on three methods of Direct Steam Generation (DSG) viz. once through, recirculation and injection of water stream and also they provide measures to design the total system. Munoz [2] in his work first time investigated heat transfer augmentation using internally helical fins in absorber tubes of PTCs. He found that, there is an increase in thermal performance by $2 \%$ and increase in cost can be just $0.5 \%$ which is very small. In case of wire coils inserts Gracia et al [11]. has done extensive work regarding heat transfer and frictional factor of wire coils for different Prandtl numbers in smooth tubes using water and propylene glycol mixture as fluid. He performed experiments for different pitch values, helix angle and wire diameters for very large range of Reynolds number (100 to 90000) and Prandtl number $(2.8-200)$. They found that wire coils causes pressure drop to increase by 8 times and heat transfer by 4 times. Choudhari \& Taji [12] in their research studied effect of wire coils inserts on heat transfer and friction factor in case of double pipe heat exchanger for different wire coils materials viz. aluminum, copper and stainless steel and different mass flow rates of fluid. They found that heat transfer augmentation is highest in case of copper compared to other two. Kim \& Seo [13] in their work did the numerical and experimental investigations of thermal performance of glass evacuated solar collectors with different shapes of absorber tube. Wang \& Sunden [14] in their paper discusses the selection of different tube inserts, and makes comprehensive comparison on the thermal and hydraulic performance for the two most common tube inserts: twisted tape insert and wire coils insert.

\section{Materials and Methods}

Performance of PTC completely depends on the absorber tubes through which working fluid flows and on which all the solar energy is focused. In the present research COMSOL Multiphysics ${ }^{\circledR} 4.4$ is used to carry out all the CFD simulations. Model consists of a hollow absorber tube through which water is flowing. Simulations for absorber tube, both with and without wire coils inserts, are carried out.

Wire coils are used for full length of tube and simulations are carried out for different pitch values and for different mass flow rates and optimum range of pitch value is proposed.

Physics used for the simulations is Non-isothermal turbulent flow, which is generally used for modeling of heat transfer in fluids, but it also provides the flexibility for heat transfer in solids. For both, the bare tube and the tube fitted with the inserts, three dimensional geometries are considered.

Geometry of wire coils can be built in COMSOL Multiphysics ${ }^{\circledR}$ using helix command. In helix one can control number of turns of wire coil, major diameter and coil diameter, radial pitch and axial pitch between two turns of coil.

The boundary conditions are set to be logarithmic wall function for all walls, constant mass flow rate for the inlet and an open boundary for the outlet. The simulations are carried out for various mass flows in the range of the experimental conditions from $0.01388 \mathrm{~kg} / \mathrm{s}$ to $0.099 \mathrm{~kg} / \mathrm{s}$. Inlet temperature of water is kept $313 \mathrm{~K}$.

Water is used as fluid by considering Direct Steam Generation (DSG) Solar Collector. To avoid complications we have assumed only single phase flows. On the outer surface of absorber tube two heat fluxes are provided, one on three fourth of the surface on which maximum of reflected sunlight light from Parabolic Trough is concentrated and on remaining surface where direct sunlight falls.

Geometry of the model is as following:

Table 1. Model geometry

\begin{tabular}{|c|c|}
\hline Parameter & Dimensions $(\mathrm{mm})$ \\
\hline $\mathrm{D}_{\mathrm{o}}$ & 26.50 \\
\hline $\mathrm{D}_{\mathrm{i}}$ & 19.50 \\
\hline $\mathrm{d}_{\mathrm{m}}$ & 17 \\
\hline $\mathrm{d}$ & 1.2 \\
\hline 1 & 250 \\
\hline
\end{tabular}

Where-

$\mathrm{D}_{\mathrm{o}}=$ Outer diameter of the tube; $\mathrm{D}_{\mathrm{i}}=$ Inner diameter of the tube; $d_{m}=$ Mean diameter of the wire coil; $d=$ wire diameter of the coil; l= Length of the tube.

For comparison of data between bare tube and tube with inserts simulations are carried out. Simulations are carried out for pitch values $6 \mathrm{~mm}, 7 \mathrm{~mm}, 8 \mathrm{~mm}, 9 \mathrm{~mm}, 10 \mathrm{~mm}, 12 \mathrm{~mm}$, $15 \mathrm{~mm}, 17 \mathrm{~mm} \& 20 \mathrm{~mm}$ for given range of mass flow rates.

In both the cases, values of Reynolds number, pressure drop \& temperature variation are obtained and accordingly values of Nusselt number and friction factors are calculated using appropriate co-relations.

Mesh size for COMSOL model is kept normal for larger areas and fine for smaller areas to reduce the computational times, still it takes quite a time for simulation as wire coils are used over complete length of tube so, the number of elements of computation are large. Heat flux values are considered $1000 \mathrm{~W} / \mathrm{m}^{2}$ and $900 \mathrm{~W} / \mathrm{m}^{2}$ for three fourth and remaining surfaces respectively which are taken from standard references.

\section{Results \& Discussion}

CFD simulation results are quite positive in terms of heat augmentation. The area where wire coils are provided, increase in turbulence is observed. This is resulting into the increase of Reynolds number (Re) thereby increasing the Nusselt number $(\mathrm{Nu})$. Prandtl number $(\mathrm{Pr})$ for all the simulation cases was found to be almost constant $(\mathrm{Pr}=$ 4.355). 
For calculation of Reynolds number, temperature difference and pressure drop in turbulent flow, k- $\varepsilon$ turbulent model is used in COMSOL Multiphysics ${ }^{\circledR}$ in which, Reynolds-Averaged Navier-Stokes equations (RANS) are used. The idea behind these equations is Reynolds decomposition, so that an instantaneous quantity is decomposed into its time-averaged and fluctuating quantities. These equations can be used with approximations based on the properties of flow turbulence to give approximate time-averaged solutions to the Navier-Stokes equations.

For our case, the heat augmentation in absorber tube is measure of the value of heat transfer coefficient, which is directly proportional to Nusselt number. For calculation of Nusselt number in case of fluid flow through circular pipes following co-relations are considered:

In case of smooth tube, the value of friction factor can be analytically calculated using

$$
f=\frac{16}{\operatorname{Re}}
$$

Now, local Nusselt number for tube side forced convection in smooth tubes for given heat flux condition can be calculated by the co-relation given by Churchill and Ozoe [7]

$$
\begin{gathered}
\mathrm{Nu}=4.36\left[1+\left(\frac{\mathrm{Gz}}{29.6}\right)^{2}\right]^{\frac{1}{6}} \\
{\left[1+\left(\frac{\frac{\mathrm{Gz}}{19.4}}{\left[1+\left(\frac{\mathrm{Pr}}{0.0207}\right)^{\frac{2}{3}}\right]\left[1+\left(\frac{\mathrm{Gz}}{29.6}\right)^{2}\right]^{\frac{2}{3}}}\right)^{\frac{3}{2}}\right]^{\frac{1}{3}}}
\end{gathered}
$$

Where Gz and Pr stand for Graetz number and Prandtl number respectively and can be given as

$$
\begin{gathered}
\operatorname{Pr}=\frac{\mu \cdot \mathrm{C}_{\mathrm{p}}}{\mathrm{k}} \\
\mathrm{Gz}=\frac{\pi}{4}\left(\frac{\frac{\mathrm{x}}{\mathrm{D}_{\mathrm{i}}}}{\operatorname{Re} \cdot \operatorname{Pr}}\right)
\end{gathered}
$$

Above co-relations which are used in simultaneously developing laminar flow, the value of local Nusselt number depends upon Graetz number and Prandtl number. For fluids with high Prandtl number hydrodynamic entry length is quite smaller compared to thermal entry length so it can be neglected.

For the flow through tube with wire coils friction factor can be evaluated using

$$
f=\frac{16.8}{(\operatorname{Re})^{0.96}}
$$

This is valid for a very large range of Reynolds number.

In case of Nusselt number we are varying the pitch of the wire coils so, the most general equation valid for this condition is

$$
\mathrm{Nu}=0.132\left(\frac{\mathrm{p}}{\mathrm{d}}\right)^{-0.372} \operatorname{Re}^{0.72} \operatorname{Pr} \wedge 0.37
$$

which is valid for $\operatorname{Re}=80-90000 \& \operatorname{Pr}=2-160$

Following figures shows the Reynolds number, pressure drop and temperature distribution results of simulation in COMSOL Multiphysics ${ }^{\circledR}$ for mass flow rate $\dot{m}=0.0333 \mathrm{~kg} / \mathrm{s}$ without wire coils:

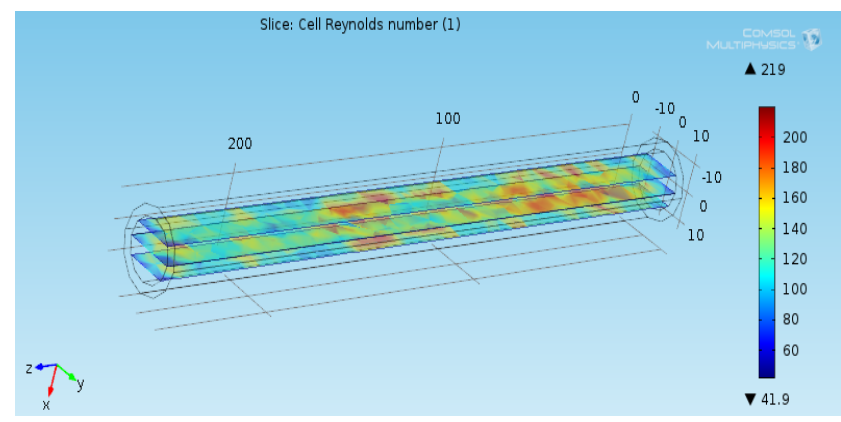

Figure 1. Reynolds number plot without wire-coil

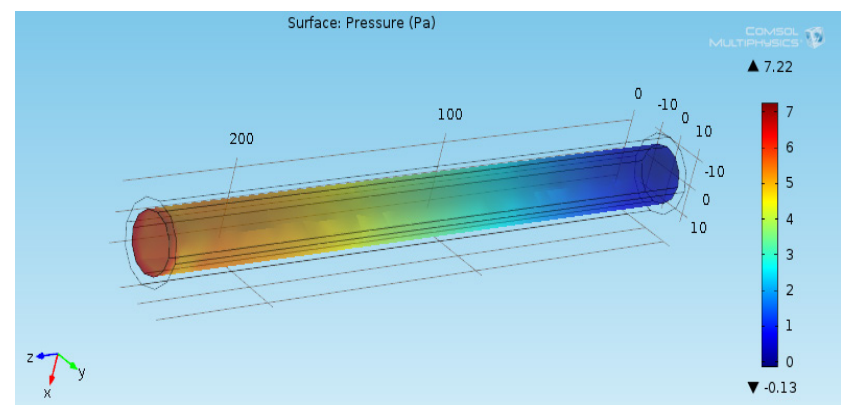

Figure 2. Pressure drop plot without wire-coil

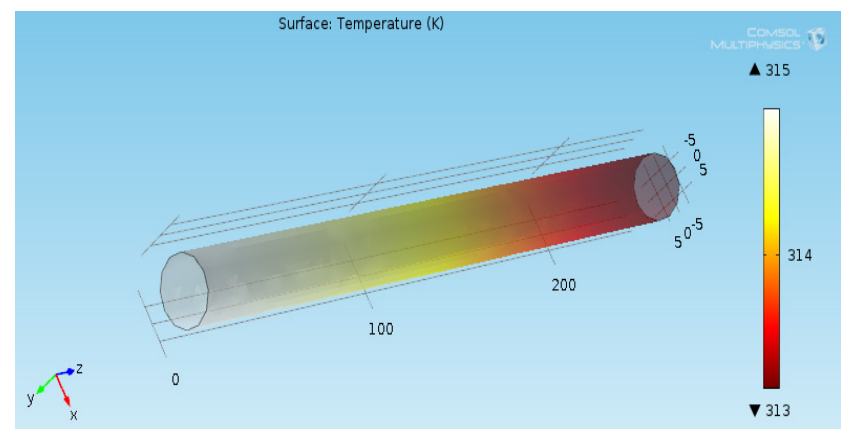

Figure 3. Temperature distribution plot without wire coil

For mass flow rate $\dot{\mathrm{m}}=0.0333 \mathrm{~kg} / \mathrm{s}$ with wire coils having pitch $\mathrm{p}=7 \mathrm{~mm}$ :

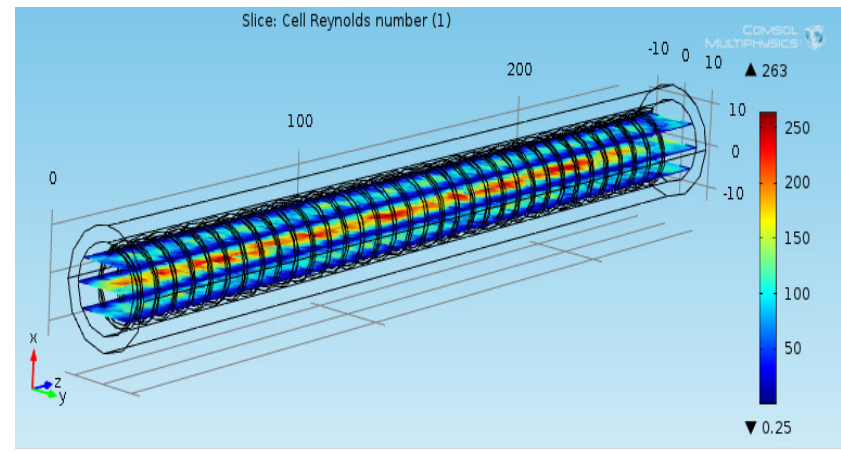

Figure 4. Reynolds number plot 


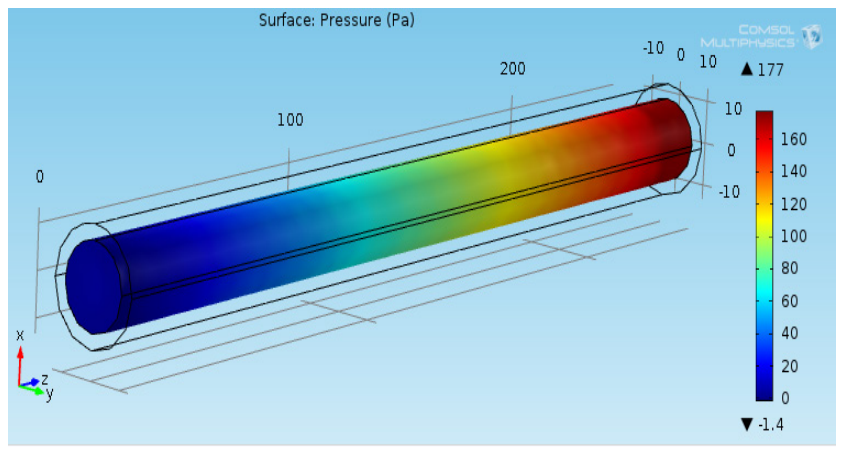

Figure 5. Pressure drop plot

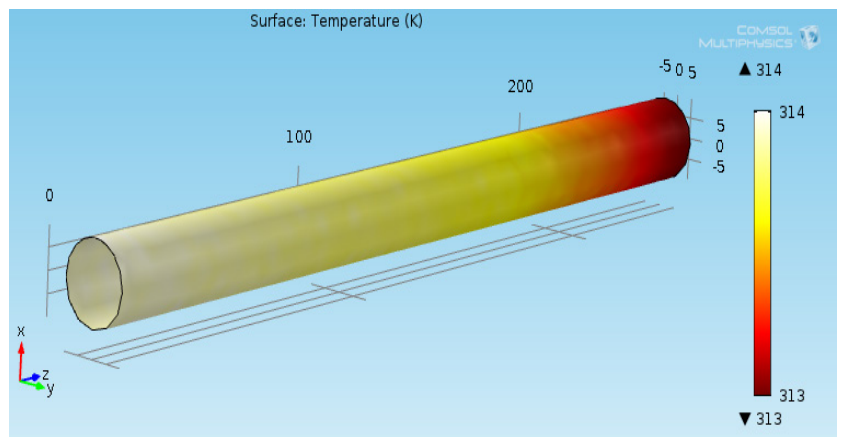

Figure 6. Temperature distribution plot

Reynolds number plot shown in figure 4 clearly indicates the disturbance i.e. the turbulence occurring in the flow because of wire coils which is evident from Reynolds number values when compared to the smooth tube flow in figure 1. Wire-coils, besides creating the turbulence also increase the overall area of heat transfer hence there is increase in convective heat transfer rate which can be observed from increased value of Nusselt number later explained in the paper.

For the mass flow rate ranging from $0.01388 \mathrm{~kg} / \mathrm{s}$ to $0.0999 \mathrm{~kg} / \mathrm{s}$ simulations for flow without wire-coils and for flow with wire-coils with variation of pitch are carried out from that, using appropriate co-relations mentioned above, the values of Nusselt number and friction factor are calculated and results are plotted graphically. For comparison the values of Reynolds number are plotted as following:

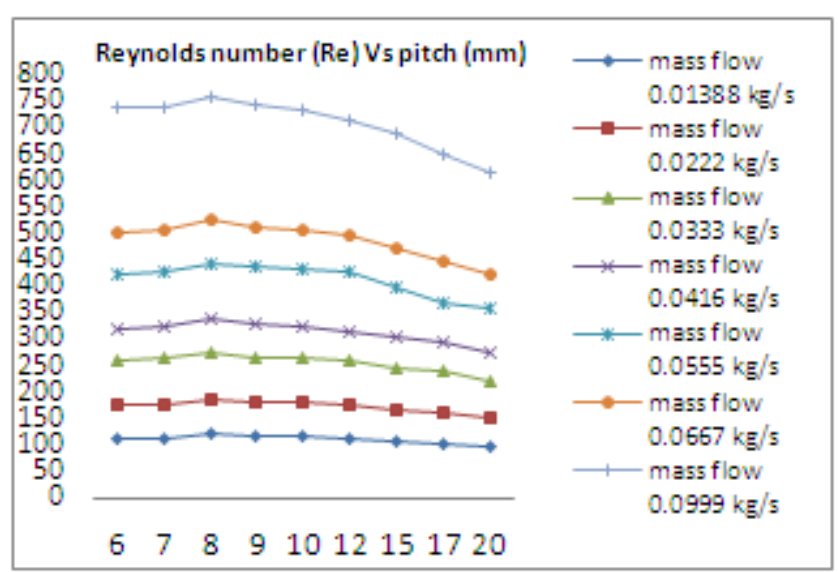

Figure 6. Variation of Reynolds number with pitch for all mass flow rates

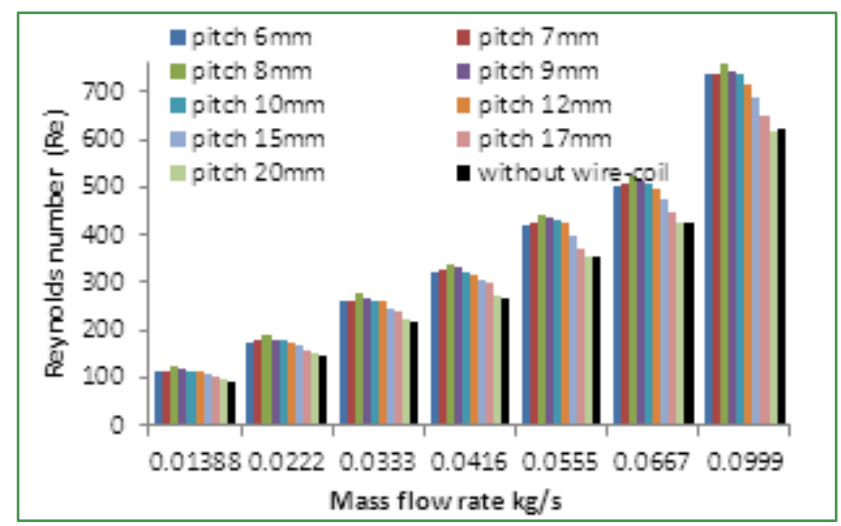

Figure 7. Variation of Reynolds number with mass flow rate for all pitch values\& flow without wire-coil

Values of Nusselt number calculated from co-relations are plotted in following two graphs (figure $8 \&$ figure 9). First graph shows variation of Nusselt number for various pitch values \& second graph compares Nusselt number values in both the cases i.e. with and without wire coils. Also, the flow through tube is always associated with pressure drop whether it's a flow with wire-coils or flow without wire coil. Figure 10 below is comparing the variation of pressure drop between flow with wire coils and flow without wire coils. Figure 11 is indicating variation of friction factor (f) variation with flow rate, with and without wire coils.

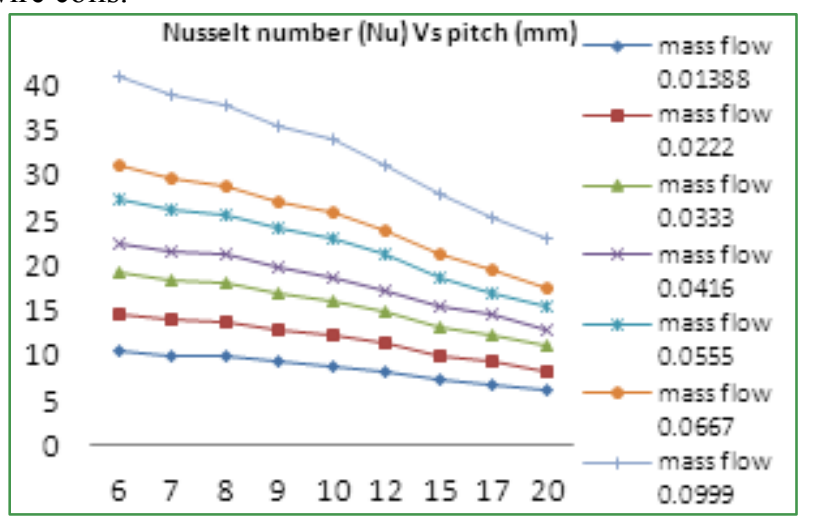

Figure 8. Variation of Nusselt number with mass flow rate for all pitch values

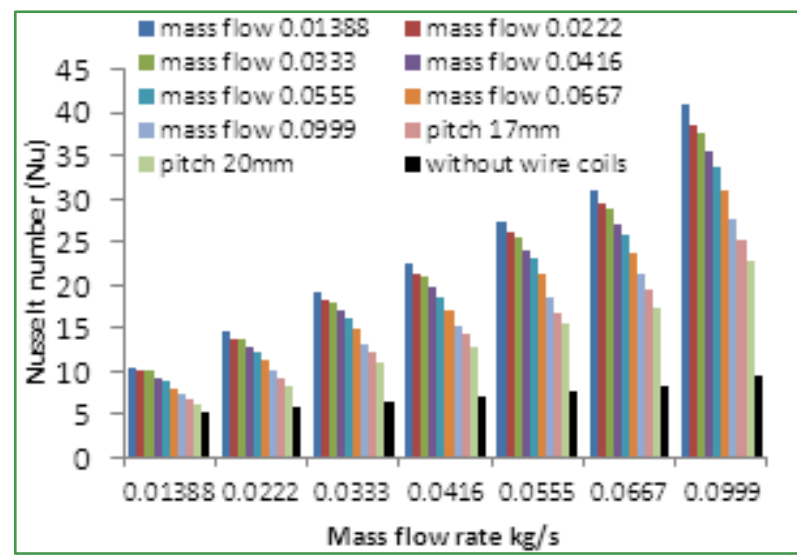

Figure 9. Variation of Nusselt number with mass flow rate for all pitch values\& flow without wire-coil 


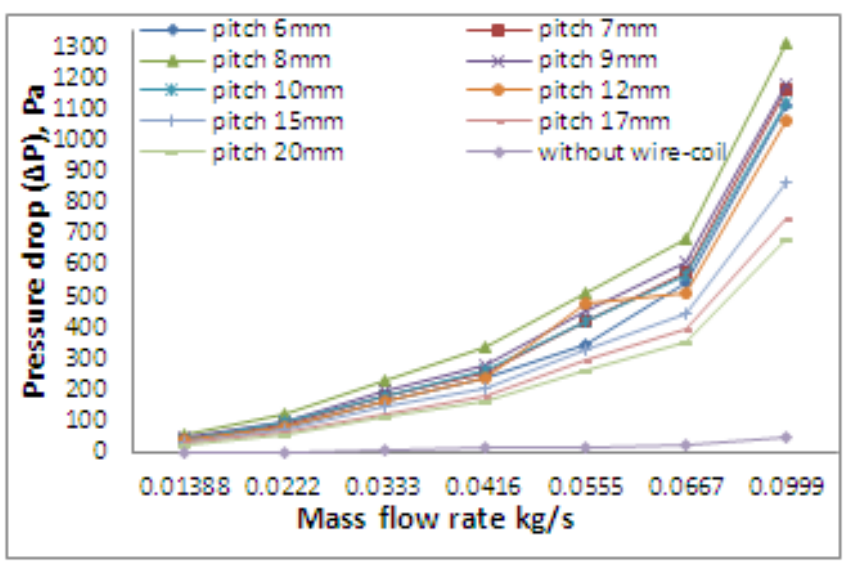

Figure 10. Variation of pressure drop

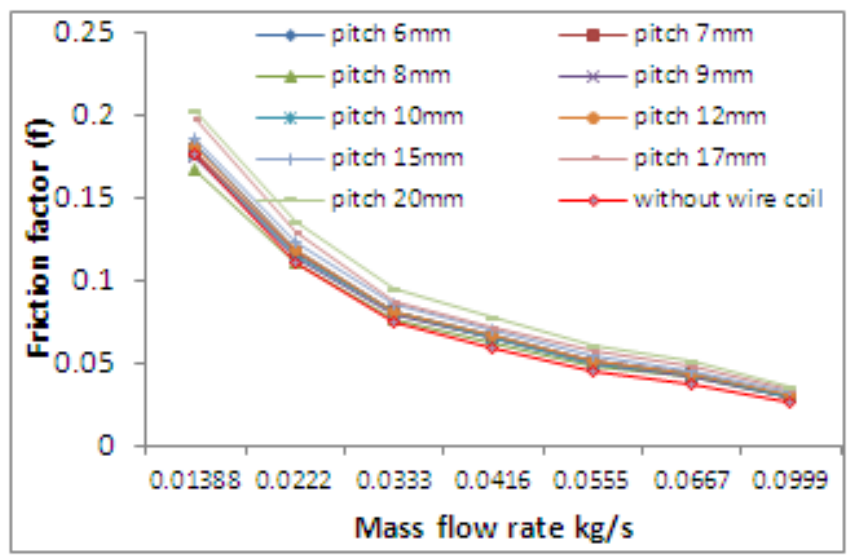

Figure 11. Friction factor variation with mass flow rate for all pitch values and withot wire coils

\section{Conclusions}

1. Reynolds number variation plot with mass flow rate for smooth tube without wire-coils and with wire-coils (figure 6 and figure 7) shows increase of Reynolds number with pitch from $6 \mathrm{~mm}$ to $8 \mathrm{~mm}$ where it becomes maximum and then it starts decreasing. All the values of Reynolds number for the flow without wire coils are observed to be less than all the values of flow with wire coils for all pitch values. But, Reynolds number values for pitch $20 \mathrm{~mm}$ are quite close to the values of Reynolds number without wire coils, so pitch value $20 \mathrm{~mm}$ is not preferable for heat augmentation purpose.

2. Nusselt number calculated from co-relations using the values of Reynolds number and Prandtl number when plotted graphically (figure 8 and figure 9) shows that, value of Nusselt number for lower flow rates remains almost constant up to $8 \mathrm{~mm}$ pitch and then decreases after that up to $20 \mathrm{~mm}$ pitch. For higher flow rates value of Nusselt number decreases continuously from $6 \mathrm{~mm}$ pitch, where maximum value of Nusselt number is obtained. So, for higher mass flow rates $6 \mathrm{~mm}$ pitch is suitable \& for lower mass flow rates pitch values range $6 \mathrm{~mm}$ to $8 \mathrm{~mm}$ is advisable. Again, it is clearly observed from above graphs that Nusselt number values for flow without wire coils are quite smaller than the flow with wire coils. The observed increase of Nusselt number with wire coils when compared with the values of tube without wire coils is minimum $104 \%$ to maximum $330 \%$ which is nothing but increase in convective heat transfer rate, so it can be clearly concluded that wire-coils inserts are indeed helping for heat transfer enhancement.

3. Pressure drop increase is always present when tube inserts are used. Pressure drop plot (figure 10) above shows this increasing trend. Maximum pressure drop is observed in case of wire-coils with pitch $8 \mathrm{~mm}$ from $55.23 \mathrm{~Pa}$ to 1311.79Pa. This increase of pressure drop is associated with pumping power which will also increase.

4. Friction factor values decreases with increase of pitch. In case of tube without wire-coils friction factor values are less than all the values of friction factor with wire coils inserts. Maximum increase of friction factor is observed to be $12.6 \%$ which is acceptable.

5. Considering all the factors discussed above we can conclude that wire-coils inserts with pitch value ranging from $6 \mathrm{~mm}$ to $8 \mathrm{~mm}$ when working with lower flow rates and pitch $8 \mathrm{~mm}$ when working with higher flow rate is advisable for better results of heat transfer enhancement.

\section{REFERENCES}

[1] Jaisankar, S., Radhakrishnan, T.K., Sheeba, K.N., Experimental studies on heat transfer and friction factor characteristics of forced circulation solar water heater system fitted with helical twisted tapes. Solar Energy 83 (11), 2009.

[2] Javier Munoz, Alberto Abanades, Analysis of internal helically finned tubes for parabolic trough design by CFD tools, Applied Energy 88 (2011) 4139-4149, May 2011.

[3] Kumar, B.N. Prasad, Investigation of twisted tape inserted solar water heaters- heat transfer, friction factor and thermal performance results, Renewable Energy 19 (2000) 379-398, February 1999.

[4] L. Valenzuela, E. Zarza, M. Berenguel, E.F. Camacho, Control scheme for direct steam generation in parabolic troughs under recirculation operation mode, Solar Energy 80 (2006) 1-17, November 2005.

[5] M. Yang and B.D. Crittenden, Use of CFD to determine effect of wire matrix inserts on crude oil Fouling conditions, Department of Chemical Engineering, University of Bath, Bath, UK, BA2 7AY.

[6] Markus Eck, Tobias Hirsch, Dynamics and control of parabolic trough collector loops with direct steam generation, Solar Energy 81 (2007) 268-279, March 2006.

[7] R. Herrero Martın, J. Perez-Garcıa, A. Garcıa, F.J. Garcia-Soto, E. Lopez-Galiana, Simulation of an enhanced flat-plate solar liquid collector with wire-coils insert devices, Solar Energy 85 (2011) 455-469, January 2011.

[8] S. D. Odeh, G. L. Morrison and M. Behnia, Modelling Of Parabolic Trough Direct Steam Generation Solar Collectors, 
PII: S0038-092X(98)00031-0, February 1998.

[9] S. Jaisankar, T.K. Radhakrishnan, K.N. Sheeba, Experimental studies on heat transfer and friction factor characteristics of Thermosyphon solar water heater system fitted with spacer at the trailing edge of twisted tapes, Applied Thermal Engineering 29 (2009) 1224-1231, June 2008.

[10] Shalini Patra, Dr. Satish Kumar Agarwal, Cfd Analysis Of Heat Transfer Augmentation For Flow Through A Tube Using Wire Coils Inserts, Department Of Chemical Engineering, National Institute Of Technology, Rourkela, 2013.

[11] Alberto Gracia, Pedro G. Vincente and Antonio Viedma, Experimental Investigation on Heat Transfer and Frictional Characteristics of Wire Coils Inserts in Transition Flows at Different Prandtl Numbers, International Journal of Heat and
Mass Transfer, 48: 4640-4651, ISSN 0017-9310, 2005.

[12] Prof.Shashank S.Choudhari, Prof. Taji S.G., Experimental Studies on Effect of Coils Wire Insert On Heat Transfer Enhancement and Friction Factor of Double Pipe Heat Exchanger, International Journal of Computational Engineering Research, Volume 03, Issue 05, May 2013.

[13] Yong Kim, Taebeom Seo, Thermal performances comparisons of the glass evacuated tube solar collectors with shapes of absorber tube, Renewable Energy 32 (2007) 772795, May 2000.

[14] Lieke Wang and Bengt Sunden, Performance comparison of some tube inserts, PII: SO7351933(01)00323-2

[15] Frank P. Incropera, David P. Dewitt, Theodore L. Bergman, Adrienne S. Lavine, Fundamentals of Heat and Mass Transfer, John Wiely \& Sons, 2006 